\title{
Focal TURP Therapy for Prostate Cancer
}

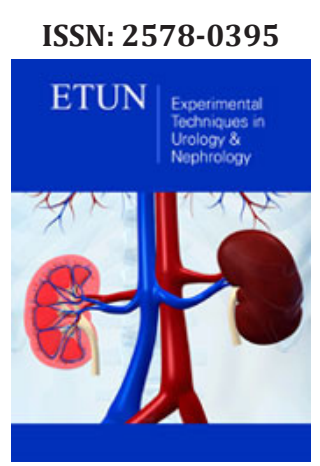

*Corresponding author: Fernando Blanco, Urology Service, Argentina Email: ferxray@gmail.com

Submission: 眥 February 27, 2019

Published: 泟 March 22, 2019

Volume 2 - Issue 5

How to cite this article: Barreiro Diego, Castro Francisco, Blanco Fernando, Colicigno Mauricio,Paz Leonardo, et al. Focal TURP Therapy for Prostate Cancer. Exp Tech Urol Nephrol. 2(5). ETUN.000550.2019.

DOI: 10.31031/ETUN.2019.02.000550

Copyright@ Fernando Blanco, This article is distributed under the terms of the Creative Commons Attribution 4.0 International License, which permits unrestricted use and redistribution provided that the original author and source are credited.

\section{Barreiro Diego ${ }^{1}$, Castro Francisco ${ }^{1}$, Blanco Fernando ${ }^{2 *}$, Colicigno Mauricio ${ }^{1}$, Paz Leonardo $^{1}$, Raush Silvia ${ }^{1}$ and Lafos Norberto ${ }^{1}$}

${ }^{1}$ Instituto de Investigaciones Médicas Alfredo Lanari University of Buenos Aires, Argentina

${ }^{2}$ Hospital Aeronáutico Central Buenos Aires, Argentina

\section{Introduction}

For the past decades, the various screening, biopsy and imaging techniques used for prostate cancer have paved the way for early diagnosis, even leading to over-treatment in certain cases. As a result, efforts have been made to find the ideal focal treatment for prostate cancer. The wide range of options for focal treatment includes: cryotherapy ${ }^{1}$, $\mathrm{HIFU}^{2}$, vasculartargeted photodynamic therapy ${ }^{3}$ percutaneous laser ablation ${ }^{4}$, brachytherapy ${ }^{5}$ and even robotic surgery ${ }^{6}$. The clinical case described below involved focal TURP as the alternative therapy for the focal treatment of prostate cancer.

\section{Clinical Case}

A 58-year-old male patient presents with elevated PSA level. Past medical history of prostate biopsy (12 samples) in 2009 with a PSA level of $8.8 \mathrm{ng} / \mathrm{ml}$ and a new biopsy (16 samples) in 2013 with a PSA level of $21.20 \mathrm{ng} / \mathrm{ml}$ (tests performed at a different center). Diagnosis of Benign Prostatic Hyperplasia (BPH) in both tests. In 2013, the patient was treated with $0.5 \mathrm{mg} /$ day of Dutasteride, reducing the PSA level to $7.75 \mathrm{ng} / \mathrm{ml}$. The treatment was continued during 2015 and in 2016 his PSA level reached $18.09 \mathrm{ng} / \mathrm{ml}$, his prostate volume was 52 grams, had a maximum flow rate of $8 \mathrm{ml} / \mathrm{sec}$, and the digital rectal examination was negative for suspicious lumps.

A multiparametric prostate MRI was requested and identified a Pi-RADS IV lesion on the right lobe, suspecting of prostate cancer (Figure 1). We suggested the patient to undergo focal TURP of the entire right lobe, including the suspicious lesion. After the surgery, it would then be possible to obtain the anatomic pathology report of the whole lesion, unblock the urinary flow and perform the eventual focal treatment of the tumour. The monopolar focal TURP of the right prostate lobe was performed, reaching the periprostatic tissues (Figure 2). The urinary catheter was kept for 14 days. One-month post-surgery the maximum flow rate reached $23 \mathrm{ml} / \mathrm{sec}$, not manifesting incontinence and maintaining the quality of erections. The anatomic pathology report revealed Gleason ${ }^{6}$ prostate cancer (Figure 3) with negative margins.

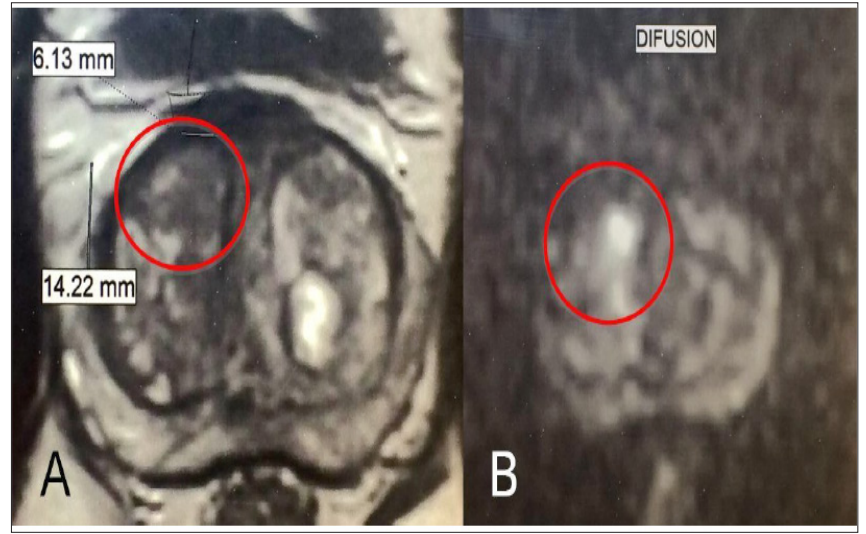

Figure 1: Multiparametric MRI: a 6.13 by 14.22 nodule is observed (inside the red circle) in transition zone (A), conditioning the mobility of water molecules with diffusion technique (B).. 


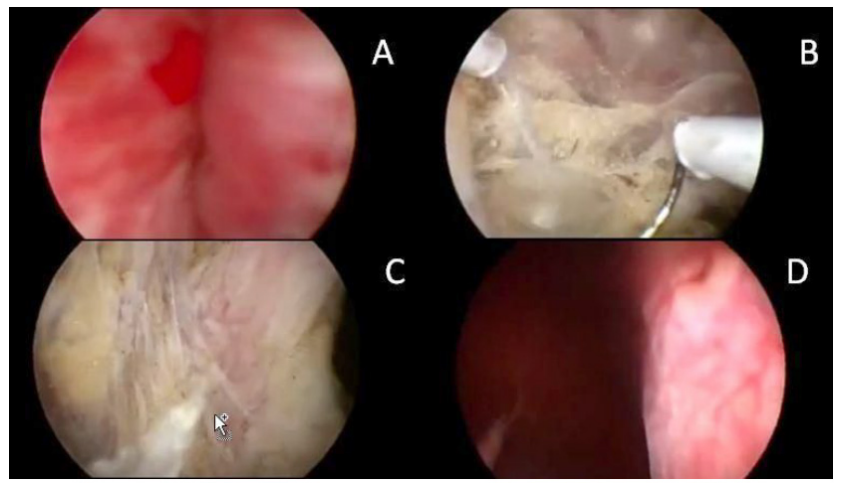

Figure 2: A: Previous urethroscopy. B: Resection as far as Denonvilleurs' fascia. C: View of peri-prostatic fat. D: Final result of entire lobe resection.

A new MRI was requested 45 days after the focal TURP at the same center, and no lesions compatible with prostatic neoformations were observed, while the whole resection of the right lobe was observed (Figure 4). A PET scan was performed
60 days later, showing no Choline uptake. The patient is now under post-treatment control. In 60 days, the PSA level went from $18.09 \mathrm{ng} / \mathrm{ml}$ down to $6.8 \mathrm{ng} / \mathrm{ml}$.

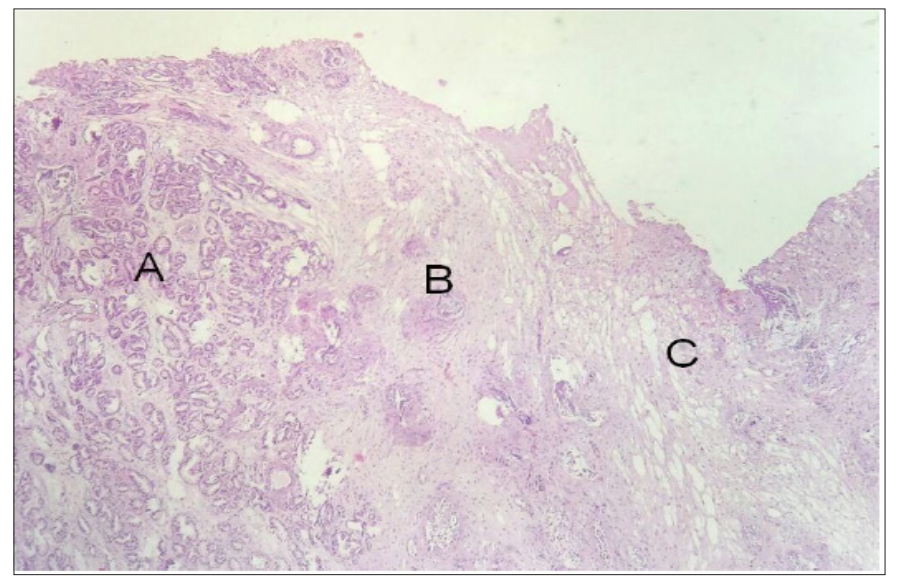

Figure 3: Histopathological study. prostate cancer (A), prostate capsule (B) and peri-prostatic fatty tissue (C) are observed. after close chip examination, no capsular invasion was found.

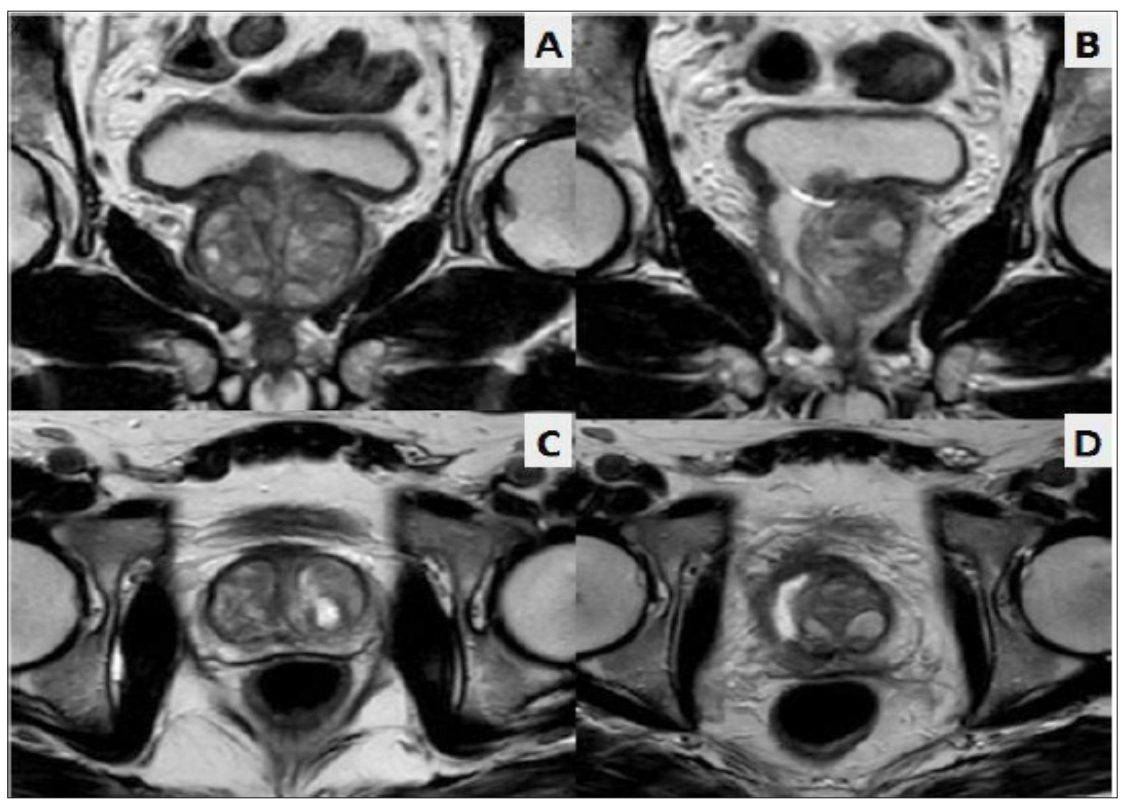

Figure 4: Comparison of pre- and post-focal TUR MRI. A: pre-focal TURP coronal slice, B: post-focal TURP coronal slice, C: pre-focal TURP axial slice, D: post-focal TURP axial slice. 


\section{Discussion}

The treatment guidelines of the European Association of Urology establish prostate cryotherapy and HIFU ("high-intensity focused ultrasound") as focal therapeutic options for clinically localized prostate cancer patients who are not eligible for $\mathrm{RP}^{7}$. The ideal candidates for prostate cryoablation are those with an organconfined disease, prostate size $\leq 40 \mathrm{ml}$, serum PSA level $<20 \mathrm{ng} / \mathrm{ml}$, and a biopsy Gleason score $<7$. Other options (vascular-targeted photodynamic therapy, percutaneous laser ablation, brachytherapy and radiofrequency) are still at an initial stage. Reuter et. $\mathrm{al}^{8,9}$., published over 1,000 radicals transurethral prostactetomies in 2012, and Morita ${ }^{10}$ suggests prostate TUR as focal prostate cancer therapy.

Unlike other focal therapies, the focal TURP resects prostatic tissue, leaving no treated tissue in situ. When performing the anatomic pathology study of the tumour that is focally treated, if the sample obtained reveals a higher Gleason score or if capsular invasion is evidenced, the patient may be switched from one focal therapy to another treatment, without waiting for disease progression to occur. The other forms of focal treatment cause a local inflammatory process which fail to unblock the patient's urinary flow and can even worsen the obstruction. In relation to the surgical technique, the focal TURP is a more laborious procedure than a traditional TUR, since hemostasis is more difficult to restore and entails a higher risk of irrigation fluid absorption. Since the procedure is under direct supervision of a urologist, rectal lesions should be less than in other forms of focal treatment.

It is a low-cost procedure which may be performed by any urologist with experience in prostate TUR. Prospective trials are needed to determine whether it really stands as a possible alternative therapy for the focal treatment of prostate cancer. It appears to be an appealing option since it unblocks the patient, whole tumor sample is taken, is a low-cost procedure and resection margins can be assessed through anatomic pathology.

\section{References}

1. Babaian RJ, Donnelly B, Bahn D, Baust JG, Dineen M, et al. (2008) Best practice statement on cryosurgery for the treatment of localized prostate cancer. J Urol 180(5): 1993-2004.

2. Poissonnier L, Chapelon JY, Rouvière O, Curiel L, Bouvier R, et al. (2007) Control of prostate cancer by transrectal HIFU in 227 patients. Eur Urol 51(2): 381-387.

3. Azzouzi AR, Barret E, Moore CM, Villers A, Allen C, et al. (2013) TOOKAD (®) Soluble vascular-targeted photodynamic (VTP) therapy: determination of optimal treatment conditions and assessment of effects in patients with localised prostate cancer. BJU Int 112(6): 766-774.

4. Colin P, Mordon S, Nevoux P, Marqa MF, Ouzzane A, et al. (2012) Focal laser ablation of prostate cancer: definition, needs, and future. Advances in Urology 2012: 1-10.

5. Schick U, Popowski Y, Nouet P, Bieri S, Rouzaud M, et al. (2011) Highdose-rate brachytherapy boost to the dominant intra-prostatic tumor region: Hemi-irradiation of prostate cancer. Prostate 71(12): 13091316.

6. Villers A, Puech P, Flamand V, Haber GP, Desai MM, et al. (2017) Partial prostatectomy for anterior cancer: short-term oncologic and functional outcomes. Eur Urol 72(3): 333-342.

7. Heidenreich A, Bolla M, Joniau S, Mason M, Matveev V, et al. (2010) Clinical guideline on prostate cancer. European Association of Urology.

8. Reuter MA, Corredera M, Epple W, Ungemach G, Verger ML, et al. (2008) Transurethral resection in prostate cancer, a radical procedure. Experience with 1017 cases. Arch Esp Urol 61(1): 13-26.

9. Reuter MA, Dietz K (2009) Radical transurethral resection of the prostate. An alternative therapy for the treatment of prostate cancer. Urologe A 48(7): 740-747.

10. Morita M, Matsuura T (2012) Management of localized prostate cancer by focal transurethral resection of prostate cancer: An application of radical TUR-PCa to focal therapy. Advances in Urology 1-8. 